\title{
Editorial
}

\section{Shared spaces: a future for JCOM}

\section{Emma Weitkamp}

\begin{abstract}
As academic communities across the globe are increasingly encouraged to share their knowledge outside the ivory towers of academia, it becomes ever more important to create a bridge that crosses continents and disciplinary boundaries. Sitting, as it does, at the nexus between science communication practice and research, JCOM has a vital role to play as just such a knowledge sharing platform.
\end{abstract}

Academic communities are increasingly being encouraged to share their ideas and knowledge with a wide range of stakeholders. This push to share knowledge beyond the ivory towers is certainly a key driver for growth in field of science communication; both in practical terms as funders seek to encourage scientists to engage with a range of publics and in research terms as interest has grown in understanding the varied aspects of public engagement. JCOM sits at this nexus, offering a platform for both practitioners and academics to share knowledge and raise common questions, as mentioned by Massarani et al. [1]. In this, the journal has a vital role to play: allowing the spread of ideas between linked but often separate communities, a topic which has come up regularly in JCOM and about which the previous editor was passionate. The previous Editorial Board also suggested that JCOM consider ways to increase reader interaction, which would also strengthen its role as a space for sharing ideas.

As I begin my tenure as Editor in Chief of JCOM, I am looking for ways to make these links stronger: to enable the journal to meet the needs of its diverse constituencies - science communication is a tremendously diverse field of practice and research and to consolidate its position as leading debates about science communication practice and research around the globe. The journal always has been open to and encouraged contributions from practitioners; but, although there are exceptions, such as Merzagora and Rodari's discussion of science communication aimed at children [2], the majority of papers and commentaries are contributed by academics. Over my tenure as editor, I would like to see a growth in articles from the practice community - both full papers and thought provoking commentaries. I know there is excellent work going on in the field across the globe; JCOM is your place to share these ideas and air the bugbears or forgotten issues faced by those in diverse practice settings. 
Commentaries, such as those on social inclusion in this issue, challenge us to reflect on our own research and practice. Dawson [3] for example, suggests that we need to rethink how we conceptualise social exclusion from science communication activities, arguing that by focusing on barriers to engagement we 'side step' reflections on whether our practices are themselves exclusive. Streicher et al. [4] argue that we should stop expecting people to come to us if we wish to reach out to unengaged communities and should, instead, go to where the people are. Similarly, Aguirre [5] describes how the Explora Science Centre in Moravia worked with the local community, one with significant poverty issues, to develop a social management strategy designed to help ensure the science centre caters for local needs. Perié et al. [6] argue that understanding scientific thinking can empower youth in conflict zones; in this case the end is not engagement with science at all, but a wider goal, that science engagement is itself empowering across many facets of society. Each of these thought provoking commentaries offers both challenges and advice to academics and practitioners alike.

My challenge to you, the readers of JCOM, is to propose your own set of commentaries that will challenge us to think outside our usual practice, to contribute thought provoking articles exploring your research or field of practice and to encourage your colleagues to read and write for the journal. It is only through your participation with JCOM that we can provide engaging and stimulating articles that challenge the science communication field to move beyond the boundaries of today. I also challenge you to make the most of the thought provoking ideas published in JCOM by using them as a starting point for wider conversations on social media and other platforms. Finally, I would like to thank the Editors and Editorial Advisory Board for their work over the past year and their continued support into the future.

\section{References}

[1] L. Massarani, M. Merzagora, N. Pitrelli, B. Trench and B. Zivcovic (2013), "New directions for JCOM", JCOM 12(02): E.

[2] M. Merzagora and P. Rodari (2013), "The challenges and the opportunities of letting children have their say", JCOM 12(03): E.

[3] E. Dawson (2014), "Reframing social exclusion from science communication: moving away from 'barriers' towards a more complex perspective", JCOM 13(02): C02.

[4] B. Streicher, K. Unterleitner and H. Schulze (2014), "Knowledge ${ }^{\circ}$ rooms - science communication in local, welcoming spaces to foster social inclusion”, JCOM 13(02): C03.

[5] C. Aguirre (2014), "Science Centers. Which role can they play to participate in a city social reconstruction?", JCOM 13(02): C04.

[6] L. Perié, L. Riboli-Sasco and C. Ribrault (2014), "Straight into conflict zones, scientific research empowers the minds", JCOM 13(02): C05. 


\section{Author}

Dr. Emma Weitkamp is a Senior Lecturer in Science Communication at the University of the West of England, Bristol where she teaches on an MSc in Science Communication and provides training in science communication for practitioners and Ph.D. students. Emma has recently been appointed as Editor in Chief of JCOM.

E-mail: Emma.Weitkamp@uwe.ac.uk.

How TO CITE: E. Weitkamp, Shared spaces: a future for JCOM, JCOM 13(02)(2014)E. 